\title{
Perfil Físico-Químico de Cervejas Artesanais e Industriais e Adequação dos Rótulos Quanto à sua Graduação Alcoólica
}

\author{
Vitória Magalhães Sousa ${ }^{1}$; Larissa Costa Silva Fogaça ${ }^{2}$
}

\begin{abstract}
Resumo: Apreciada por muitos consumidores, a cerveja é um produto alcóolico de consumo expressivo no Brasil, com processo industrial altamente consolidado. Entretanto as cervejas produzidas de forma artesanal têm se destacado entre os consumidores, por apresentarem sabores mais acentuados. Dessa forma, objetivou-se com o estudo determinar o perfil físico-químico de cervejas artesanais e industriais comercializadas no município de Vitória da Conquista - Bahia, bem como a avaliação da adequação dos rótulos dessas quanto à sua graduação alcóolica. As amostras das cervejas foram escolhidas de forma aleatória e estas foram avaliadas quanto ao $\mathrm{pH}$, acidez, extrato seco, densidade relativa e teor alcóolico. Os resultados evidenciaram que as cervejas atendem aos padrões exigidos pelo Ministério da Agricultura Pecuária e Abastecimento (MAPA) que determina os requisitos mínimos para garantia da qualidade das cervejas industriais, contudo, o valor da densidade relativa das amostras apontou um valor inferior ao padrão estabelecido e observaram-se divergências entre o teor alcóolico descrito no rótulo com o teor alcóolico obtido, necessitando assim de análises mais precisas para a avaliação destes.
\end{abstract}

Palavras-Chave: Artesanal; Industrial; Físico-Químico.

\section{Physical-Chemical Profile Of Artisan And Industrial Beers And The Adequacy Of The Labels Regarding Their Alcoholic Graduation}

\begin{abstract}
Appreciated by many consumers, beer is an alcoholic product of significant consumption in Brazil, with a highly consolidated industrial process. However, artisan-made beers have stood out among the consumers, because they have more pronounced flavors. The objective of this study was to determine the physico-chemical profile of artisanal and commercial beers sold in the city of Vitória da Conquista, Bahia, as well as the evaluation of the adequacy of these labels for their alcoholic strength. Samples of the beers were randomly selected and evaluated for $\mathrm{pH}$, acidity, dry extract, relative density and alcohol content. The results evidenced that the beers meet the standards required by the Ministry of Livestock and Food Supply (MAPA), which determines the minimum requirements for quality assurance of industrial beers, however, the value of the relative density of the samples indicated a value lower than the established standard and differences were observed between the alcohol content described on the label and the alcohol content obtained, thus requiring more precise analyzes for the evaluation of these.
\end{abstract}

Keywords: Artisanal; Industrial; Physical-Chemical.

\footnotetext{
${ }^{1}$ Graduanda em Farmácia pela Faculdade Independente do Nordeste, FAINOR, Brasil. vitooriamagalhaes@ gmail.com;

${ }^{2}$ Orientadora. Mestrado em Engenharia de Alimentos pela Universidade Estadual do Sudoeste da Bahia, Brasil. Professor da Faculdade Independente do Nordeste, Brasil
} 


\section{Introdução}

A indústria cervejeira no Brasil possui grande expressividade, ocupando a terceira posição como maior produtor de cerveja do mundo, com uma produção de 14 bilhões de litros por ano, sendo a bebida alcoólica mais consumida no país (CERVBRASIL, 2018). Dados do Ministério da Agricultura, Pecuária e Abastecimento (MAPA) indicam um crescimento de 37,7\% no número de cervejarias registradas no Brasil em 2017. É importante ressaltar que em 2017 foram contabilizadas 679 cervejarias, ante 493 de 2016 (BRASIL, 2018).

O MAPA é um órgão do governo que regulamenta o setor cervejeiro para cumprimento de determinadas leis que visam qualificar essa produção com certas características físico-químicas e sensoriais a serem seguidas (ANDRADE et. al., 2016). Elaborada com malte de cevada, água, lúpulo e fermento (levedura), a cerveja é uma bebida carbonada com baixo teor alcoólico (ANDRADE et al., 2016).

O processo de produção de cervejas é designado por algumas etapas importantes, como a brasagem, que consiste na mistura das matérias-primas com a água dando origem ao mosto cervejeiro; a fermentação, onde é adicionada a levedura ao mosto consumindo os carboidratos fermentáveis produzindo etanol e $\mathrm{CO}_{2}$; a maturação, que proporciona um aprimoramento do sabor da cerveja; a filtração e o envasamento (ROSA e AFONSO, 2015). Vale ressaltar que, todas essas substâncias devem ser de boa qualidade, livre de contaminação.

Atualmente existem duas formas de fabricação de cervejas, sendo essas: as industriais, feitas normalmente por empresas de grande porte e em larga escala e as artesanais, que usualmente é para consumo próprio e feitas por produtores amadores, mas que vem conquistando espaço no mercado.

As cervejas industriais - mesmo que firmadas no mercado brasileiro - estão continuamente em procura de melhoria para a geração de produtos de cada vez mais qualidade e baixo custo, com o intuito de permanecerem nesse ramo cada vez mais rigoroso (ALMEIDA e BELO, 2017). Já a produção de cerveja artesanal vem ganhando muito destaque entre os consumidores da cerveja produzida industrialmente, principalmente entre os apreciadores de uma cerveja mais requintada (FLORES et. al., 2015).

As cervejas artesanais se diferem das industriais normalmente pelos ingredientes que constituem a bebida, pois além dos componentes essenciais como a água, o malte, o lúpulo e a levedura, existem itens que são adicionados para aprimoramento destas, sendo esses mais selecionados. As etapas de produção também são realizadas de forma artesanal, sem todos os 
aparatos industriais sendo, portanto mais controladas e sem adição de produtos químicos para aceleração de processos (FLORES et al., 2015).

A rotulagem deste tipo de bebida deve seguir certas diretrizes previstas na lei que incluem exibir nas embalagens itens como: marca; quantidade de bebida medida em volume; composição; grau alcoólico; prazo de validade; indicação do lote de fabricação; endereço do produtor no MAPA, além de expor advertência para impedir ou minimizar o consumo exagerado de álcool (ANDRADE et. al., 2016). A RDC nº 259/02 é a resolução que determina o regulamento para a rotulagem de alimentos embalados, sejam eles de qualquer tipo e qualquer origem (ALMEIDA, 2014).

Diante do exposto, objetivou-se com o presente estudo determinar o perfil físico-químico de cervejas artesanais e industriais comercializadas em Vitória da Conquista - Bahia, bem como a adequação dos rótulos dessas quanto à sua graduação alcóolica, visando garantir a qualidade das cervejas e das informações contidas na rotulagem destas.

\section{Material e Método}

O presente estudo consiste em uma pesquisa experimental, descritiva de abordagem quantitativa, realizada nos Laboratórios de Saúde da Faculdade Independente do Nordeste FAINOR.

Foi realizado um levantamento de espécies de cervejas artesanais e outras industriais comercializadas em garrafas de vidro na cidade de Vitória da Conquista - Bahia, das quais foram analisadas seis amostras em dois lotes, com diferentes períodos de produção. $\mathrm{O}$ grupo de amostragem totalizou 6 cervejas artesanais e 6 cervejas industriais, analisadas em triplicata.

As cervejas foram descarbonatadas conforme instruções do Instituto Adolfo Lutz (2008) e analisadas quanto ao potencial hidrogeniônico $(\mathrm{pH})$, acidez, densidade relativa, teor alcoólico e extrato seco total. Os resultados foram corroborados com os padrões estabelecidos pelo decreto do MAPA n ${ }^{\circ}$ 6.871/2009, assim como os rótulos avaliados quanto ao cumprimento do estabelecido na legislação brasileira. Já a graduação alcoólica foi certificada a partir das análises realizadas em comparação com o teor alcoólico já descrito no rótulo de cada cerveja.

O potencial hidrogeniônico $(\mathrm{pH})$ foi medido com o auxílio do $\mathrm{pHmetro} \mathrm{que} \mathrm{permite} \mathrm{uma}$ determinação direta, simples e precisa do $\mathrm{pH}$, conforme metodologia do Instituto Adolfo Lutz (2008). A densidade relativa foi realizada com o auxílio do picnômetro que proporciona 
resultados precisos e são construídos de modo a permitir a pesagem de volumes exatamente iguais de líquidos, a uma dada temperatura (IAL, 2008).

A graduação alcoólica foi realizada conforme metodologia descrita pelo MAPA (BRASIL, 2010) e pelo Instituto Adolfo Lutz (2008), através do método de destilação, com separação do álcool e posterior quantificação através da densidade relativa do destilado obtido a $20^{\circ} \mathrm{C}$. Os valores de densidade relativa foram convertidos utilizando a Tabela de Conversão a $20^{\circ} \mathrm{C} / 20^{\circ} \mathrm{C}$ em porcentagem de álcool, segundo Instituto Adolfo Lutz (2008).

O extrato seco total foi realizado pelo método de evaporação da água e álcool, das bebidas descarbonatadas, com posterior pesagem do material residual (BRASIL, 2010). A acidez foi realizada através da volumetria de neutralização, que se baseia na titulação dos ácidos com uma solução básica padronizada, com uso de indicador fenolftaleína (IAL, 2008).

\section{Resultados e Discussão}

Os resultados das análises físico-químicas realizadas nas amostras de cervejas artesanais e industriais comercializadas no município de Vitória da Conquista - BA estão dispostos na Tabela 1.

Tabela 1. Resultados das análises físico-químicas das cervejas industriais e artesanais.

\begin{tabular}{cccccccc}
\hline Amostra & Produção & pH & AT & ES & DR & TA & TADR \\
\hline A & Artesanal & 4,45 & 37,8 & $6,68 \%$ & 0,9903 & $5,4 \%$ & $6,0 \%$ \\
B & Artesanal & 4,38 & 29,7 & $6,65 \%$ & 0,9906 & $5,35 \%$ & $6,0 \%$ \\
C & Artesanal & 4,40 & 37,8 & $6,41 \%$ & 0,9939 & $3,35 \%$ & $5,4 \%$ \\
D & Artesanal & 4,42 & 37,6 & $6,43 \%$ & 0,9937 & $3,45 \%$ & $5,4 \%$ \\
E & Artesanal & 4,44 & 37,8 & $7,89 \%$ & 0,9943 & $3,15 \%$ & $6,0 \%$ \\
F & Artesanal & 4,45 & 38,2 & $7,74 \%$ & 0,9944 & $3,15 \%$ & $6,0 \%$ \\
G & Industrial & 4,65 & 35,1 & $3,30 \%$ & 0,9922 & $4,4 \%$ & $4,4 \%$ \\
H & Industrial & 4,55 & 38,7 & $3,40 \%$ & 0,9924 & $4,25 \%$ & $4,4 \%$ \\
I & Industrial & 4,24 & 29,7 & $4,25 \%$ & 0,9917 & $4,65 \%$ & $4,8 \%$ \\
J & Industrial & 4,29 & 27,0 & $4,16 \%$ & 0,9916 & $4,75 \%$ & $4,8 \%$ \\
K & Industrial & 4,75 & 37,8 & $4,25 \%$ & 0,9916 & $4,75 \%$ & $4,8 \%$ \\
L & Industrial & 4,70 & 32,4 & $4,16 \%$ & 0,9917 & $4,70 \%$ & $4,8 \%$
\end{tabular}

Fonte: Dados da pesquisa (2018). AT - Acidez Total (meq/L); ES - Extrato Seco; DR - Densidade Relativa (g); TA Teor Alcoólico ( $\left.{ }^{\circ} \mathrm{GL}\right)$; TADR - Teor Alcoolico Descrito no Rótulo. 
A cerveja é um produto considerado ácido, na qual os valores aceitáveis de $\mathrm{pH}$ entre elas variam entre 4-5 (ALMEIDA e BELO, 2017). Nas análises feitas foram encontrados diferentes níveis de $\mathrm{pH}$. Identificou-se que todas as amostras se encontram dentro das normas de regularização, variando entre 4 e 5 . A amostra L foi a que indicou menor pH sendo 4,25. Já a amostra $\mathrm{K}$ foi a que indicou maior $\mathrm{pH}$ sendo 4,75.

A acidez total encontrada nas cervejas pode ser considerada um indicador de contaminação bacteriana, mas não é um teste efetivo para afirmar tal fato. O tipo de produção e a matéria prima contida em uma cerveja podem aumentar o nível de acidez total do produto, assim como a elevação da acidez pode ocorrer a partir da contaminação do líquido, por microrganismos, durante a sua produção (ALMEIDA e BELO, 2017).

Os níveis de acidez das amostras A, C, E e K foram iguais indicando 37,8 meq/L. As amostras I e B também indicaram acidez igual sendo 29,7 meq/L. Em estudos realizados com cervejas artesanais do tipo Pale Ale (Pontes et. al., 2016), foram encontrados teores de acidez que variaram entre 19,07 a 46,02 meq/L, semelhantes aos encontrados neste estudo. Os parâmetros para acidez total não são determinados pela legislação (BRASIL, 2009), sendo esta análise realizada com o objetivo de qualificar as cervejas quanto a sua acidez (PONTES et. al., 2016).

Os valores obtidos para densidade relativa variaram entre 0,9903 a $0,9944 \mathrm{~g}$, estando estes abaixo do estabelecido pela legislação que determina que a densidade deve variar entre 1,007 a 1,022 (BRASIL, 2009). A determinação da densidade relativa das cervejas analisadas permitiu a conversão desta para graduação alcóolica, a partir da Tabela de Conversão $20^{\circ} \mathrm{C} / 20^{\circ} \mathrm{C}$ do Instituto Adolf Lutz (2008).

O MAPA estabelece como "cerveja com álcool” aquela cujo percentual de álcool for superior a $0,5 \%$ em volume, devendo obrigatoriamente apresentar a sua graduação alcoólica descrita no rótulo (ALMEIDA e BELO, 2017). Todas as amostras avaliadas possuem em seus rótulos os níveis de graduação alcoólica definidos. A cerveja artesanal é reconhecida por possuir um teor alcóolico mais elevado, como visto na tabela 1 de 6\%. Já as cervejas industriais possuem um teor menor de $4,4 \%$.

A graduação alcóolica descrita no rótulo foi comparada a graduação obtida na análise, a partir da densidade relativa e os resultados encontram-se descritos no Gráfico 1. Todas as amostras apresentaram um teor alcóolico superior ao determinado pelo MAPA, para ser considerada como "cerveja com álcool". Entretanto, observou-se discrepâncias entre o valor obtido e o definido no rótulo, com exceção da amostra $\mathrm{G}$ que obteve valor equivalente de 4,4\%. 


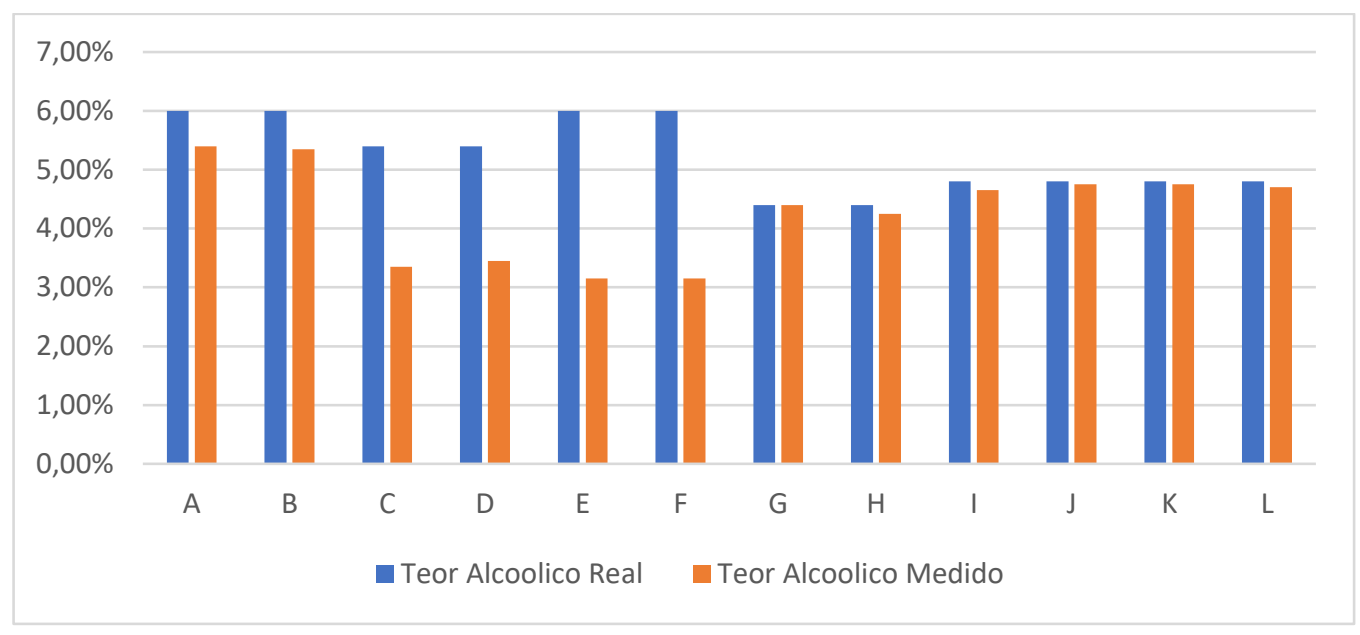

Gráfico 1. - Comparação do teor alcoólico real com o medido.

As discrepâncias observadas no teor alcóolico das cervejas podem ser resultado da metodologia utilizada, pois segundo Almeida e Belo (2017) existem metodologias que são mais precisas, European Brewing Convention, Beer Judge Certification Program e a American Society of Brewing Chemists, que avaliam a evolução da graduação alcóolica desde o processo produtivo, avaliando o mosto, até o produto acabado.

O extrato real, ou comumente chamado de extrato seco é a resultante dos sólidos inseridos na composição de uma cerveja. $\mathrm{O}$ valor dele é variante conforme o aumento ou diminuição da taxa de evaporação da água. Ou seja, quanto mais compostos permanecerem contidos na cerveja após a evaporação da água, mais encorpadas elas serão consideradas, já que possuem maior nível de extrato real. Em cerveja, os valores de extrato seco devem estar entre 2,0 e 7,0\%, sendo os valores acima de 3,0\% como valores determinantes para uma boa qualidade da cerveja (ALMEIDA e BELO, 2017).

Utilizando como base as informações acima, durante o estudo das amostras foi constatado que a maioria está de acordo com os valores padrões. Entretanto, a amostra E possui um nível diferenciado, ultrapassando os valores considerados normais, chegando a cerca de $7,89 \%$, destacando-se entre as cervejas artesanais. Enquanto, as industriais variaram entre $3,30 \%$ a 4,25\%. É importante salientar que os valores maiores de extrato seco encontrados nas análises são referentes as amostras de cervejas artesanais, visto que essas são mais encorpadas devido a sua maior composição de outras substâncias, ou pelo fato destas passarem ou não pela etapa de filtração no seu processo produtivo, diferindo-se assim das cervejas industriais. (PONTES et. al., 2016). 


\section{Conclusões}

O estudo realizado avaliou o perfil físico-químico de cervejas artesanais e industriais comercializadas na cidade de Vitória da Conquista - Bahia, a partir de análise quantitativa de parâmetros pré-estabelecidos pela legislação. Os resultados evidenciaram valores de $\mathrm{pH}$ e extrato seco dentro dos padrões exigidos pelo Ministério da Agricultura Pecuária e Abastecimento (MAPA). As cervejas artesanais destacam-se como maiores teores de extrato seco, devido à sua composição e processo produtivo. Os valores obtidos para a acidez apresentou resultados satisfatórios quanto à qualidade microbiológica do produto, visto que esta é uma análise que não possui parâmetros estabelecidos pela legislação.

As amostras apresentaram densidade relativa menor que os valores estimados para cervejas e os resultados para o teor alcóolico medido apresentaram disparidades na maioria das amostras do valor alcóolico descrito no rótulo. Essas diferenças podem estar relacionadas à metodologia utilizada, que se utiliza do processo de destilação comum, sendo ideal o acompanhamento a partir de softwares específicos para avaliação desde o processo produtivo, para construção deste teor alcóolico. As cervejas de produção artesanal apresentaram maiores valores para o teor alcóolico. A avaliação da qualidade das cervejas é de suma importância para que o consumidor tenha maior segurança no consumo de um produto que é altamente apreciado pela população, garantindo assim que todos os padrões estabelecidos estejam de acordo.

\section{Referências}

BRASIL. Decreto $n^{\circ}$ 6.871, de 04 de junho de 2009. Regulamenta a Lei $\mathrm{n}^{\circ} 8.918$, de 14 de julho de 1994, sobre a padronização, a classificação, o registro, a inspeção e a fiscalização da produção e do comércio de bebidas. Diário Oficial da União, Brasília, 04 de junho de 2009.

BRASIL. Manual de Métodos de Análises de Bebidas e Vinagres, caderno 4 Fermentados Alcoólicos. Ministério da Agricultura, Pecuária e Abastecimento-MAPA. Secretaria de Defesa Agropecuária- SDA, Coordenação Geral de Apoio Laboratorial-CGAL, 2010.

BRASIL. A cerveja no Brasil. Ministério da Agricultura, Pecuária e Abastecimento. - MAPA. Disponível em: file://C:/Users/Usuario/Downloads/A\%20CERVEJA\%20NO\%20BRASIL28.08.pdf. Acesso em: abril de 2018.

CERVBRASIL. Associação Brasileira da Indústria de Cerveja. Anuário 2016. Disponível em: http://www.cervbrasil.org.br/site/anuarios/CervBrasil-Anuario2016_WEB.pdf Acesso em: abril de 2018. 
INSTITUTO ADOLFO LUTZ, IAL. Normas analíticas do Instituto Adolfo Lutz. Métodos físicos e químicos para análise de alimentos. $4^{\circ}$ ed., v. 1, 2008.

LIMBERGER, S. C.; TULLA, A. F. A emergência de microcervejarias diante da oligopolização do setor cervejeiro (Brasil e Espanha). Centro de Estudos Geográficos. Finisterra, LII, n. 105, p. 93-110, 2017.

ANDRADE, A. W. L.; LIMA, E. F. B.; MEIRELLES, L. M. A. Avaliação da rotulagem e qualidade de diferentes marcas de cerveja tipo pilsen. Centro Universitário Uninovafapi Revista Interdisciplinar.vol. 9,n²,p. 49-56. 2016.

ALMEIDA, R. A. F. Avaliação da adequação de rotulagem de cervejas tipo Pilsen produzidas no Brasil e comercializadas no Ceará. Nutrivisa - Revista de Nutrição e Vigilância em Saúde. vol.2, n², p. 72-78; 2014.

FLORES, A. B.; GRAFF, A.; CORNELIUS, E.; SOUZA, C. F. V. Perfil sensorial e avaliações físico-químicas de cerveja artesanal de chocolate e caramelo. Revista Destaques Acadêmicos. vol. $7, \mathrm{n}^{\circ} 4$, p. 158-166. 2015.

ROSA, N. A.; AFONSO, J. C. A química da cerveja. Química nova escola. vol.37, n² 2, p. 98105. 2015.

ALMEIDA, D. S. de; BELO, R. F. C. Análise físico-química de cervejas artesanais e industriais comercializadas em Sete Lagoas - MG. Faculdade Ciências da Vida - FCV. 2017. Disponível em: jornal.faculdadecienciasdavida.com.br/index.php/RBCV/article/download/362/232 Acesso em: outubro de 2018.

PONTES, D. F.; MIRANDA, K. W. E.; ZAMBELLI, R. A.; PINTO, L. Í. F.; GOIANA, M. L. Análises Físico-Químicas de Cervejas Artesanais Pale Ale Comercializadas em Fortaleza, Ceará. Fundação de Apoio da Universidade Federal do Rio Grande do Sul. 2016. Gramado - RS. Disponível em: http://www.ufrgs.br/sbctars-eventos/xxvcbcta/anais/files/768.pdf Acesso em: novembro de 2018.

Como citar este artigo (Formato ABNT):

SOUSA, Vitória Magalhães; FOGAÇA, Larissa Costa Silva. Perfil Físico-Químico de Cervejas Artesanais e Industriais e Adequação dos Rótulos Quanto à sua Graduação Alcoólica. Id on Line Rev.Mult. Psic., 2019, vol.13, n.43, p. 440-447. ISSN: 1981-1179.

Recebido: 27/11/2018;

Aceito: 28/11/2018 